\title{
The Teaching Reform of 'Signals and Systems' for Excellent Talents Cultivation
}

\author{
Yongqi Wang \\ School of Electronic and Electrical Engineering \\ Shanghai University of Engineering \\ Shanghai, China \\ Email:wangyongqi17008@163.com
}

\author{
Chen Deng \\ School of Electronic and Electrical Engineering \\ Shanghai University of Engineering \\ Shanghai, China
}

\author{
Xiaoxiao Jiang \\ School of Electronic and Electrical Engineering \\ Shanghai University of Engineering \\ Shanghai, China
}

\begin{abstract}
Excellent engineer education training plan', which is put forward by the Ministry of Education, aims to develop innovative engineering and technical personnel with a global vision. Therefore, teaching mode of the 'signals and systems' has become current research focus in order to establish an effective Innovation Talents Training Goal. In this paper, new teaching mode of the 'signals and systems' Course toward the excellent training objectives is researched and explored from curriculum teaching methods, teaching arrangements, practical teaching and teaching staff building.
\end{abstract}

Keywords-Excellent Talents cultivation; 'signals and systems', teaching reform

\section{INTRODUCTION}

In recent years, the higher engineering education of China has made great achievements, the scale of education has been ranked first in the world, and China has become a veritable engineering education power. However, China's higher engineering education is not strong and not fine, and is generally lack of practice and innovation, so talent training in higher education can't fully meet the needs of social and economic development. In view of this, the Ministry of Education officially launched the 'Excellence Engineer education technology'(referred to as the 'excellence' hereinafter) pilot projects in some universities in 2010 [1], to train a group of various types of engineering and technical personnel with strong practicality and innovation to meet the needs of social and economic development[2-3].

\section{THE BUIDING OF TEACHING STAFF Is FUNDAMENTAL}

In the process of cultivating talents in colleges and universities, teachers and courses are the key determinant. Only emphasizing on one side can not achieve the ideal teaching effect. Teacher training is the premise of educational reform, and the key to the success of reform lies in the participation of teachers. Only when teachers agree with the idea of reform, participate in the reform process, the success of reform will be attained [4]. The reform of teaching methods, teaching means and teaching content can be achieved only through the teachers The teacher professional development is an important internal support force of curriculum reform, and effective curriculum leadership is an important external support system for teachers to participate in curriculum reform, only combining them together can promote the process of education reform. The teacher is not only to impart knowledge, and he should also be a facilitator of the comprehensive development of students. Therefore, in the course of teacher training, the teacher's personality, humanistic quality, education reflection ability, creative ability, development and utilization ability of curriculum resources and the ability to support students' effective learning ability are put forward higher requirements.

Over the years, we have always attached importance to the building of teaching staff, and have organized a team of competent teaching staff with the construction of 'signals and systems' excellent course. The course teaching staff has 6 people ( 3 doctors and 3 masters) with 1 professor, 2 associate professors and 3 lecturers, and the teaching team is organized by taking the professor as the leading, the associate professors as the backbone and the lecturers as the support. The team has a reasonable distribution of age and title and a reasonable structure of high level teaching team. These teachers engage in the teaching of 'signals and systems' and in teaching and scientific research, are responsible for or participate in a number of research projects, have strong research ability and have group advantages in teaching and research for many years The team actively carrys out research activities, promotes the teaching with scientific research, pays attention to timely penetrate scientific research into the teaching, constantly improves the level of the classroom teaching, and lays the foundation for the students to explore new ideas and understanding the frontier. The team has guided students to design and complete some projects, at the same time, the team organizes teaching and research activities every week in the 
process of teaching, dynamic organizes teaching contents with the development of the major, discusses teaching method and teaching means according to the teaching content, solves new problems in a timely manner, and achieves shared resource. The teaching team is a 'double facet' teaching team, which is both engaged in teaching and engineering practice.

\section{THE BUILDING OF TEACHING MATERIAL IS THE GUARANTEE OF THE CULTIVATION OF APPLIED TALENTS}

The building of teaching material is an important part of the course construction. It not only is the specific embodiment of the training objectives and basic requirements of the curriculum, but also reflects the teaching philosophy of teachers. Therefore, the building of teaching materials can reflect the reform achievement of the course system and teaching content with the aim of cultivating Excellent Talents. In the construction of teaching materials, we should pay attention to reflect the basic and advanced material, to reflect the cognitive process and the cognitive law of human, to reflect the inner link between teaching contents, to embody the major characteristics, especially to focus on the relationship between theory and engineering practice.

So, we have compiled a new series of textbooks on 'signals and systems'. While we write the main textbook, we make multimedia courseware companion, and we plan to gradually write "The guide of "signals and systems"' and "The experiment notes of "signals and systems", to establish the teaching website of 'signals and systems' to upload the teaching video online, and constitute a harmonious and complete three-dimensional teaching material system. Compared with the previous similar materials, the main teaching textbooks have the following innovative points:

\section{A. Emphasize the Discrete part of the Content to Meet the Needs of Computer Science}

Because the 'signals and systems' course is a professional basic course, its important function is to lay the foundation for the follow-up courses. With the use of computers and related courses supplementing to the teaching plan for electronics majors, especially for computer science, in order to meet the needs of the following courses and new technology development, strengthen the discrete 'signals and systems' analysis is imperative in the teaching process of 'signals and systems' course. Based on this, the main textbook will analyze the discrete part and the continuous part in parallel, and then emphasize the importance of the discrete part.

\section{B. Each Chapter Is Equipped with Examples and Exercises to Enhance the Content of Attractiveness}

According to the specific content of each chapter, add new application examples into the textbook based on the latest technology of the current communication (such as network communication, 3G Technology), automatic control (such as system design, space technology), signal processing (such as analog and digital filter, image processing and so on), and based on the experience of the teachers' scientific research and practice for years. At the same time, provide in each chapter with an appropriate amount of exercises which are related to practice. This can avoid students only aiming to solve the questions, help to stimulate students' learning interest and enthusiasm, promote the students to understand and grasp the basic concepts.

\section{Application of MATLAB}

Students can enhance the understanding of this course and the ability to analyze and solve problems by using MATLAB. In order to strengthen the combination of theoretical knowledge and practice, to cultivate students' ability of application and engineering quality, there is one special chapter in the textbook which is set up with an aim to discuss the application of MATLAB in the analysis of 'signals and systems'. At the same time, according to the characteristics of the course, design the simulation experiments based on MATLAB, students should complete the experiment content by analyzing the processing and the function of the system of analog signals on the computer, which replaces traditional test of the experiment box. At the same time, it can also review and strengthen some of the important concepts in the 'signals and systems' course. The consolidation and verification of 'signals and systems' analysis will help to improve students' ability to solve problems by using computer aided analysis method. The advanced and applicable textbook not only has a significant effect on promoting the modernization of teaching and improving the quality of teaching, but also can cultivate students' innovative consciousness. The building of 'signals and systems' teaching material involves the educational thought, the teaching content, the talent training specification, the knowledge structure and so on, which is a systematic engineering and fundamental engineering. The building of 'signals and systems' teaching material requires educators to change educational concept, to take the quality of education as the center, to combine knowledge imparting, ability cultivating and quality improving together, to organize the three integrated, and to achieve satisfactory teaching effect through continuous improvement.

\section{THE REFORM OF TEACHING METHODS IS THE NECESSARY MEANS}

The core of teaching reform is the reform of teaching method, which is mainly reflected in the course's classroom teaching. In the classroom teaching, how to realize the change from the teacher-centered to the students as the main body and the teacher as the director? How to change from one-way infusion to the interaction between teachers and students? How to combine knowledge imparting with comprehensive ability training? We conducted exploration and practice in-depth and use three teaching methods in the classroom teaching of the signal and the system course.

\section{A. Implementation of the 'Problem-driven' Teaching Method}

The aim of Excellent Talent cultivation emphasizes on cultivating the students' ability to discover, analyze and solve problems. 'Problem-driven' teaching method is that the teacher introduces the teaching contents by setting questions or asking questions, guides the students to think and encourages the students to answer questions. The correct use of this method has a positive effect on improving the students' quality and 
learning interest, mobilizing the initiative of students, cultivating students' creative ability. Organize the teaching activities around the issue to inspire students to think consciously and take the initiative to explore, to guides students to continuously find problems, put forward problems, analyze problems and finally solve the problem, which cultivates students' creative thinking.

The key of 'problem-driven' teaching method is to find out the entry point of the teaching theme to arouse students' strong interests and to produce internal dynamics of learning, and then leads the interest to the discussion of teaching contents. For example, in the teaching of 'signals and systems', before the introduction of some important theories, the teacher can introduce and set question points through a example or a practical engineering problem, make students thinking in a exciting state, then discusses and finally summarize and make a real-time interactive classroom test. As long as the teacher carefully designs, a lot of teaching content can be found as an appropriate entry point. The design of this teaching method can make students fully integrated into the classroom, make the classroom atmosphere becomes active, make students' learning enthusiasm aroused, so it stimulates students' participation awareness and desire for knowledge.

\section{B. The Use of Modern Teaching Methods}

By the use of MATLAB's powerful waveform-plot and numerical calculation ability, the complex mathematical calculation and transform becomes simple and clear, which helps students' sight to change from the teaching calculation process to the physical meaning of the calculation results. MATLAB also provides a powerful tool for visualization and analysis of the system. MATLAB has the powerful toolbox function to analyze the continuous signal, continuous system, also can analyze discrete signals and discrete systems, and can carry out various analysis and calculation of the signal, such as addition, multiplication, translocation, inversion, the Fourier transform, The Laplace transform, $\mathrm{Z}$ transform calculation, and so on. If the teacher can combine the graphics to assist teaching, he can achieve twice the result with half the effort, thus get improved teaching quality and efficiency [5].

\section{Combining the Content of the Course with the Current New Technolog to Assign Extra-curricular Activities}

In the actual teaching process, in addition to assignments in the textbooks, the teacher should find the entry points to modern advanced technology, find students' interesting points and the application areas of the 'signals and systems' theory related to the teaching content timely. Such as, after studying the frequency domain analysis of the 'signals and systems', some questions can be proposed based on the students' most familiar mobile phone and Internet technology: Why the phone numbers are different? What is the difference between the first generation of mobile phones and the GSM mobile phones in communication principle? Why GSM and CDMA mobile phone cards can not be exchanged? What does $3 \mathrm{G}$ mean? What is the function of modem in network communication?

\section{PRACTICE IS A POWERFUL PlatFORM}

Excellent Talents training requires that engineering higher education should aim at the comprehensive quality education, rather than the examination oriented education. The traditional teaching model must be developed to improve students' comprehensive quality, theory and practice, and to cultivate students' innovative spirit and innovative ability as the key point. Practice teaching reform plays an important role in the process of achieving this goal. The practice teaching of 'signals and systems' is divided into two aspects, the experiment and the curriculum design.

\section{A. Experimental Part}

'Signals and systems' experiment can deepen the understanding of the 'signals and systems', help the students to master the actual 'signals and systems' processing technology. The experimental class is not the supplementary of classroom teaching or inessential in the form, but the extension of classroom teaching. Experimental teaching and theoretical teaching is a unified organism. According to the hierarchical division of the experimental teaching goal, we divide the experiment into two levels.

1) Basic experiments based on hardware experiment box. The basic experiment is mainly presented so as to demonstrate and verify the principle and the abstract knowledge. The aim is to cultivate students' ability of practice and practical operation. There are a total of 4 basic hardware experiments designed in 'signals and systems' course, i.e., 'the use of digital oscilloscope', 'zero input and zero state response', 'the decomposition and synthesis of non-sinusoidal periodic signal', and 'frequency characteristic test of the linear system'.

2) Simulation experiments based on MATLAB. The experiments of 'signals and systems' simulation based on MATLAB are comprehensive experiments. Comprehensive experiments summarize and sublimate the knowledge of 'signals and systems', integrate some of the distributed theoretical knowledge points, and have links to other courses and practical system, broaden and deepen the students' knowledge, realizes the transition from knowledge points to knowledge planes, cultivates students' innovation and scientific research quality. The simulation experiments based on MATLAB haVE a total of 5 experiments, they are 'analysis and synthesis of periodic signal spectrum', 'sampling and recovery of rectangular pulse signal', 'zero pole system function and stability analysis', 'signal modulation and demodulation' and 'design and verification of frequency filter'.

Using MATLAB, each student can do the experiment independently, and even students can break through the limit of time and space to complete the experiment using the computer in any place, submit the simulation and experimental results by e-mail or other forms. This method has great flexibility, which helps to improve the learning efficiency. Secondly, by the combination of computer simulation technology and network technology in the course of the experiment, the remote simulation experiment is integrated into the network teaching, and improve the distance teaching system. 
B. Independent Course Design based on a Variety of College Students Design Competition

The course designed is to train the students to master and apply the basic theory, basic knowledge and basic skills of the 'signals and systems' according to the cultivating objective of Excellent Talents. A series of science and technology competitions, such as, National Undergraduate Electronic Design Contest and the College Students' Innovative Design Contest, are helpful to the implementation of quality education, the cultivation of students' innovative ability, cooperative spirit and the ability of link theory with practice in the study, and are helpful to train students practice ability and improve students' ability of electronic design to the actual problem.

Encourage students to design on their own, such as, 'design of digital spectrum analyzer', 'design of data acquisition and transmission system', and 'audio signal analyzer'. These topics are to improve students' innovation consciousness and practical ability. The advantage of college student independent design competition is, based on the same topic, different students may have completely different design process, which not only exercise the students ability to analyze and solve problems independently and the ability of creative thinking, but also make students understand new trends to the scientific development at the first time and grasp the new technology as soon as possible.

\section{CONCLUSION}

'Signals and systems' is a course of theory and practice, and the requirements of teachers, equipment, teaching methods and practice are very high. Along with the strategic adjustment of our country's socialist market economy system and the economic structure, the demand of the applied talents from the society will be more and more. This requires us to increase the training of talents, and the teaching thought and method are adjusted accordingly under the new training targets.

These are the ideas and practices of our 'signals and systems' course teaching team, and there must be many shortcomings. But we hope to play a role and establish a set of the new modes in the course of 'signals and systems' under the goal of cultivating Excellent Talents. We will continuously improve the educational theory during the teaching practice, guide practice by the educational theory, and explore an effective way of Cultivating Applied Talents.

\section{ACKNOWLEDGMENT}

This work was supported by platform course construction of 'signals and systems' of Shanghai University of Engineering (k201602004).

\section{REFERENCES}

[1] Lin Jian. The reforms of the implementation of the plan of Cultivating Excellent Engineer [J]. China Higher Education, 2010(10) : 30-32

[2] Yu Jin-xia, Jia Zong-pu,Tang Yong-li. The teaching practice of IT specialty with the aim of cultivating students' creative ability [J]. Computer Education, 2014(22): 107-110
[3] BI Ping, LIU Yu. Teaching Reform and Practice of 'signals and systems' for the Project of 'Outstanding Engineers' $[\mathrm{J}]$. Research and Exploration in Laboratory, 2014(1): 190-193.

[4] Zhu Jiong-lin,Fang Zhu-fang. A Study of the Optimization Strategy for Training Young Teachers in the University Transformation[J]. Journal of Zhejiang University of Technology(Social Science), ,2014,13(1): 7174

[5] Li Nian-nian, Zhang Hong-mei, Software Design for 'signals and systems' Analysis Based on Maltab GuI[J]. Industrial Control Computer, 2011,24(3):19-21. 